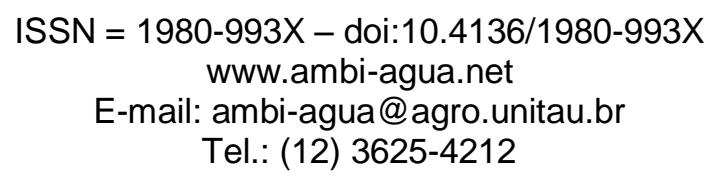

\title{
Caracterização química da água subterrânea em área ocupada por cemitério: uso da técnica de espectrometria de fluorescência de raios-X por energia dispersiva (EDXRF)
}

\author{
(http://dx.doi.org/10.4136/ambi-agua.911) \\ Pedro Daniel da Cunha Kemerich ${ }^{1}$; José Luiz Silvério da Silva ${ }^{2}$; Guilherme Barros ${ }^{3}$; \\ Willian Fernando de Borba ${ }^{3}$; Fernando Ernesto Ucker ${ }^{4}$; Cristian Vargas Foletto ${ }^{5}$ \\ ${ }^{1}$ Universidade Federal de Santa Maria, Frederico Westphalen-RS, \\ e-mail: eng.kemerich@yahoo.com.br, \\ ${ }^{2}$ Universidade Federal de Santa Maria, Santa Maria-RS, \\ e-mail: silverioufsm@gmail.com, \\ ${ }^{3}$ Universidade Federal de Santa Maria, Frederico Westphalen-RS, \\ e-mail: guilherme_barrosp@hotmail.com, borba_willian@hotmail.com, \\ ${ }^{4}$ Universidade Federal de Goiás, Goiânia-GO, \\ e-mail: ferucker@hotmail.com, \\ ${ }^{5}$ Centro Universitário Franciscano, Santa Maria-RS, \\ e-mail: cv.foletto@bol.com.br.
}

\section{RESUMO}

Geralmente, o enterro do ser humano pode contribuir para a poluição da água subterrânea, quando do contato com o lixiviado gerado a partir da decomposição dos corpos na zona não saturada do subsolo. O monitoramento desse tipo de atividade foi realizado neste trabalho, que teve como objetivo a determinação da qualidade da água subterrânea em zona ocupada por cemitério. Para isto, utilizou-se a técnica de Espectrometria de Fluorescência de Raios-X por Energia Dispersiva (EDXRF) para a caracterização química da água subterrânea. Foram construídos cinco poços de monitoramento, de acordo com os padrões brasileiros. Foi estimada a flutuação do lençol freático, a superfície potenciométrica e as concentrações dos elementos cálcio, cobre, ferro, fósforo e silício. O Nível da água apresentou-se bastante superficial, variando entre 0,48 a $0,95 \mathrm{~m}$ no período seco. A concentração de cálcio variou entre 4,65 a $17,85 \mathrm{mg} \mathrm{L}^{-1}$, cobre entre $0,02 \pm 0,29 \mathrm{mg} \mathrm{L}^{-1}$, ferro variou de 0,57 a $15,96 \mathrm{mg} \mathrm{L}^{-1}$, fósforo entre 12 a 13,98 $\mathrm{mg} \mathrm{L}^{-1}$, e por último o silício, variando entre 35,55 a 79,12 $\mathrm{mg} \mathrm{L}^{-1}$. Conclui-se que o uso da técnica de EDXRF demonstrou ser rápida e eficiente para quantificação de alguns constituintes em águas subterrâneas coletadas em poços de monitoramento sob a influência de cemitério em terreno silto-argiloso.

Palavras-chave: lixiviado, poços de monitoramento, constituintes.

\section{Chemical characterization of groundwater in the area occupied by the cemetery: use of fluorescence spectrometry X-ray energy dispersive (EDXRF)}

\begin{abstract}
Generally, the burial of human corpses can contribute to groundwater pollution by the contact of leachate generated from the decomposition of bodies in the unsaturated zone of the subsoil. This process has been investigated in this work that aimed to determine the overall
\end{abstract}


KEMERICH, P. D. C.; SILVA, J. L. S.; BARROS, G.; BORBA, W. F.; UCKER, F. E.; FOLETTO, C. V. Caracterização química da água subterrânea em área ocupada por cemitério: uso da técnica de espectrometria de fluorescência de raios-X por energia dispersiva (EDXRF). Ambi-Agua, Taubaté, v. 7, n. 3, p. 166-182, 2012. (http://dx.doi.org/10.4136/ambi-agua.911)

quality of groundwater in the zone occupied by the cemetery. The fluorescence spectrometry X-ray Energy Dispersive (EDXRF) technique was used for groundwater chemical characterization. Five monitoring wells were constructed according to Brazilian norms. The water level fluctuation, the potentiometric surface and the concentrations of the elements calcium, copper, iron, phosphorus and silicon were estimated. The water level appeared quite shallow, ranging between 0.48 to $0.95 \mathrm{~m}$ in the dry season. The concentrations range for calcium varied from 4.65 to $17.85 \mathrm{mg} \mathrm{L}^{-1}$, for copper $0.02 \pm 0.29 \mathrm{mg} \mathrm{L}^{-1}$, iron 0.57 to 15.96 $\mathrm{mg} \mathrm{L}^{-1}$, phosphorus 12.00 to $13.98 \mathrm{mg} \mathrm{L}^{-1}$, and silicon 35.55 to $79.12 \mathrm{mg} \mathrm{L}^{-1}$. It is concluded that the use of EDXRF techniques proved to be rapid and efficient for monitoring the constituents in the groundwater collected in wells under the influence of graveyard in silt-clay soil.

Keywords: leachate, monitoring wells, constituents.

\section{INTRODUÇÃO}

Dos aproximados 3\% de água doce no planeta, cerca de $22 \%$ são águas subterrâneas. Com a população aumentada em seis vezes e consumo de água doce no planeta triplicou nos últimos 50 anos, os recursos hídricos disponíveis estão com sua qualidade comprometida e, como consequência, a utilização das águas das reservas subterrâneas vem aumentando (Vasconcelos et al., 2006).

Alguns impactos ambientais relacionados às águas subterrâneas podem ser provenientes de cemitérios, considerando que na construção da maioria destas necrópoles não são levados em conta estudos geológicos e hidrogeológicos. Desta forma, estas instalações podem representar certo risco de contaminação durante a decomposição dos corpos. A localização dos cemitérios ocorre, preferencialmente, em áreas afastadas do centro urbano, porém hoje é possível encontrar cemitérios totalmente integrados à malha urbana (Migliorini, 2002).

Os cemitérios, como qualquer outra instalação que afete as condições naturais do solo e das águas subterrâneas, são classificados como atividade com risco de contaminação ambiental. A razão disso é que o solo em que estão instalados funciona como um filtro das impurezas depositadas sobre ele. O processo de decomposição de corpos libera diversas substâncias que constituem o organismo humano, como os metais, somando-se a isso nos caixões são utilizados diferentes utensílios metálicos ou não que podem liberar substâncias para a o solo e a água subterrânea (Kemerich et al., 2012).

Como principal causa de poluição nos cemitérios, durante a decomposição dos cadáveres é liberado um líquido denominado necrochorume. Esta é uma solução aquosa rica em sais minerais e substâncias orgânicas degradáveis, de tonalidade castanho-acinzentada, viscosa, de cheiro forte e com grau variado de patogenicidade (Silva et al., 2006).

Com intuito da preservação do meio ambiente entrou em vigor a Resolução No 335/2003 do Conselho Nacional do Meio Ambiente (CONAMA), sobre as condições mínimas necessárias para o licenciamento ambiental de cemitérios no Brasil, alterada pela Resolução CONAMA N 368/ 2006. (CONAMA, 2003; 2006)

A utilização de técnicas para determinação multielementar tem se desenvolvido muito nos últimos anos devido ao aumento de análises químicas para uma grande variedade de matrizes. Em função disto, a Fluorescência de Raios-X de Energia Dispersiva (EDXRF) mostra-se como uma técnica muito versátil, podendo ser aplicada em diversas amostras, incluindo as de estado sólido e líquidas, sem necessitar de tratamento exaustivo para a preparação destas matrizes, e também oferecendo a grande vantagem de ser um método analítico não-destrutivo (Schimidt et al., 1999). Wastowski et al. (2010) aplicaram o método para caracterização dos níveis de 
KEMERICH, P. D. C.; SILVA, J. L. S.; BARROS, G.; BORBA, W. F.; UCKER, F. E.; FOLETTO, C. V. Caracterização química da água subterrânea em área ocupada por cemitério: uso da técnica de espectrometria de fluorescência de raios-X por energia dispersiva (EDXRF). Ambi-Agua, Taubaté, v. 7, n. 3, p. 166-182, 2012. (http://dx.doi.org/10.4136/ambi-agua.911)

elementos químicos em solos concluindo ser esta técnica como uma importante alternativa, com crescente aplicação na identificação mineralógica de solos, rochas, cerâmica e líquidos, uma vez que permite a determinação simultânea ou seqüencial da concentração de todos os elementos enquadrados entre o Sódio (Na) e o Urânio (U). Como vantagens relatam que não há necessidade de destruição da amostra, ou seja de modo instrumental, sem nenhum prétratamento químico e podendo atingir limites de detecção da ordem de 1 a 20 ppm. Pataca et al. (2005) aplicaram com sucesso a técnica (EDXRF) na determinação de arsênio em águas contaminadas.

Com base no tema exposto, este trabalho tem como objetivo geral determinar a qualidade da água subterrânea em área ocupada por cemitério em Zona de Afloramentos do Sistema Aquífero Guarani/SAG. E como objetivos específicos: (a) Utilizar a técnica de Espectrometria de Fluorescência de Raios-X por Energia Dispersiva (EDXRF) na caracterização química da água subterrânea em poços de monitoramento; (b) Espacializar as concentrações dos parâmetros analisados na área de influência do cemitério; (c) Comparar os resultados com as normas e legislações vigentes Portaria Ministério da Saúde №518/2004, Resoluções CONAMA No396/2008 e No420/2009 (CONAMA, 2008; 2009).

\section{MATERIAIS E MÉTODO}

\subsection{Caracterização Geológica da Área de Estudo}

O local de estudo situa-se no perímetro urbano de Santa Maria, no Estado do Rio Grande do Sul, está localizado na Borda de Bacia do Paraná na Depressão Central. Esta transição com o Planalto é constituída de acordo com Gasparetto et al. (1990) por rochas sedimentares clásticas arenosas pertencentes às Formações Rosário do Sul, Santa Maria (Membro Passo das Tropas e Membro Alemoa), Caturrita e Botucatú.

Essa sequência de rochas sedimentares clásticas é constituída por interdigitações de: arenitos, siltitos, argilitos, concreções calcárias (calcretes), além de apresentar, localmente, em algumas dessas formações um conteúdo de répteis fósseis. Essas unidades hidroestratigráficas podem constituir Aquíferos, Aquitardos ou Aquicludos (Maciel Filho, 1990; CPRM, 1994; Machado, 2005).

Em termos hidrogeológicos o Município de Santa Maria assenta-se sobre importantes aquíferos na área urbana, os quais estão relacionados às unidades Hidroestratigráficas Sanga do Cabral, Santa Maria (Aquífero Passo das Tropas I e II), Caturrita e Botucatu (Machado, 2005). Todos associados com arenitos, com potencial aquífero, mas nem sempre preenchidos por água. Normalmente as águas subterrâneas são doces, potáveis, porém algumas se apresentam salobras com elevado conteúdo de sais dissolvidos (CPRM, 1994; Fachin, 2003 e 2005).

A Unidade Hidroestratigráfica Alemoa é constituída por camadas interdigitadas de siltitosargilosos maciços, concreções carbonáticas e localmente forma sítios de fósseis répteis do Período Triássico. Constitui-se basicamente por lamitos impermeáveis que funcionam como Aquicludo, não armazenando nem transmitindo (Maciel Filho, 1990; CPRM, 1994). Já Böger e Kowalcyk (1993) ainda incluíram nesta unidade a ocorrência de fácies de areias muito finas, as quais podem ser aquíferos. Os argilominerais presentes são principalmente da família das esmectitas expansiva e também formam interestratificados I-S (Silvério da Silva et al., 1990; 2010; Silvério da Silva, 1997). A estrutura originalmente maciça devido à exposição aos agentes intempéricos torna-se fissurada, apresentando fissilidade, o que pode vir a facilitar o fluxo de contaminantes gerados na superfície do terreno. Maciel Filho (1990) 
KEMERICH, P. D. C.; SILVA, J. L. S.; BARROS, G.; BORBA, W. F.; UCKER, F. E.; FOLETTO, C. V. Caracterização química da água subterrânea em área ocupada por cemitério: uso da técnica de espectrometria de fluorescência de raios-X por energia dispersiva (EDXRF). Ambi-Agua, Taubaté, v. 7, n. 3, p. 166-182, 2012. (http://dx.doi.org/10.4136/ambi-agua.911)

considerou esta unidade impermeável em sua capa superior, enquanto que os siltitos e arenitos argilosos da base são semi-permeáveis. Após períodos chuvosos pode haver alguma acumulação de água nas fissuras associadas à zona vadosa, isto não significa o nível freático da unidade, o qual, a rigor não se forma, uma vez que a unidade forma Aquicludo. Machado (2005) estimou uma espessura da ordem de $150 \mathrm{~m}$.

\subsection{Cemitério Santa Rita de Cássia}

O cemitério estudado nesta pesquisa é do tipo parque jardim, denominado Santa Rita de Cássia, fundado no mês de outubro de 1970, junto a rodovia RS 509, km 4 no Município de Santa Maria - RS. Ele conta atualmente com 6000 sepulturas e vem recebendo em média 15 corpos por mês. Situa-se em área de expansão urbana contíguo ao Cemitério Municipal São José, no Bairro Pé de Plátano. Este se localiza em área de afloramentos e zona de recarga do SAG, mais especificamente na Unidade Hidroestratigráfica Alemoa (Machado, 2005).

\subsection{Construção dos Poços de Monitoramento}

A locação dos poços de monitoramento obedeceu à conformação do terreno, à disposição das sepulturas e a direção do fluxo subterrâneo que em condições normais acompanha a superfície do terreno formado por uma vertente suave. Foram construídos cinco poços de monitoramento denominados PM1, PM2, PM3, PM4 e PM5. Sendo que o PM1 encontra-se na cota altimétrica mais elevada, distante das sepulturas sendo por isso considerado o branco ou controle (background), seguido dos demais, em cotas altimétricas decrescentes, em direção a rodovia RS-509.

Os poços de monitoramento foram construídos com o auxílio de um trado mecânico pelo método rotativo direto, com broca de $300 \mathrm{~mm}$ de diâmetro conforme visualizado na Figura 1a, seguindo-se as orientações da NBR 15.495 (ABNT, 2007), conforme ilustra a figura 1b, selo sanitário (Figura 1c), constituído de argamassa de cimento e areia buscando-se evitar a contaminação da água dos poços pelo escoamento superficial. Cada poço recebeu uma tampa e rotulagem contendo sua numeração e data de construção.

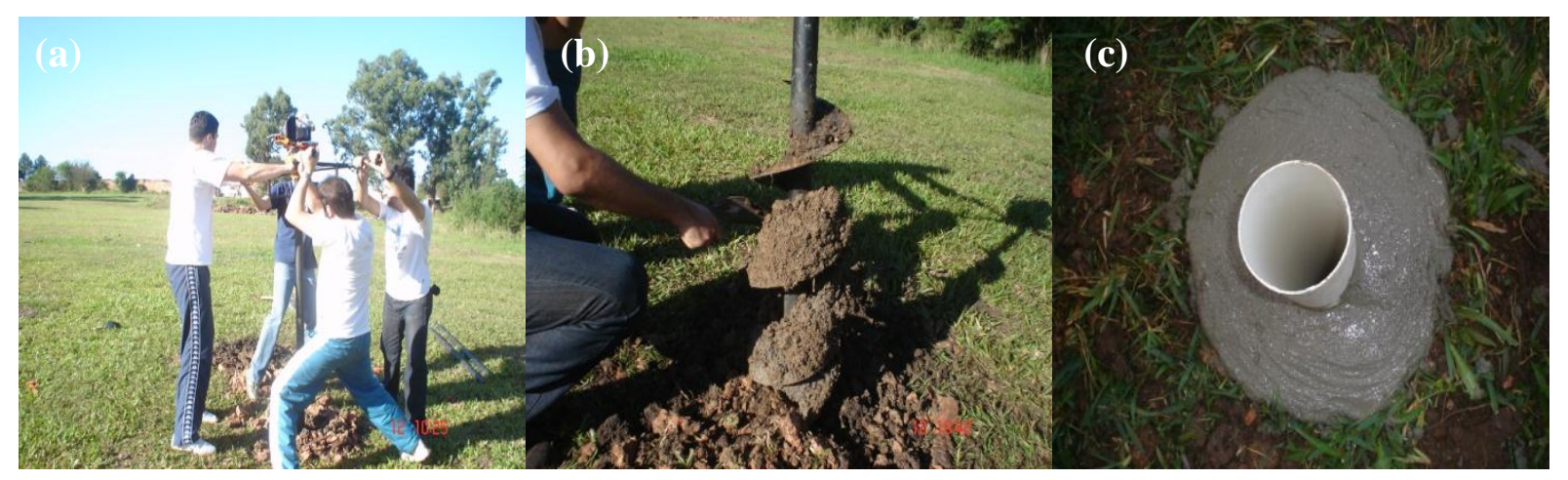

Figura 1. Utilização do trado mecânico para construção dos poços de monitoramento.

\subsection{Método de Amostragem}

Durante a realização das amostragens, as amostras de água foram retiradas dos poços de monitoramento com um amostrador dotado de válvula anti-retorno, previamente esterilizado. Para o acondicionamento foram utilizadas garrafas plásticas de $2000 \mathrm{~mL}$, devidamente rotuladas e identificadas de acordo com o número dos poços estudados. 
KEMERICH, P. D. C.; SILVA, J. L. S.; BARROS, G.; BORBA, W. F.; UCKER, F. E.; FOLETTO, C. V. Caracterização química da água subterrânea em área ocupada por cemitério: uso da técnica de espectrometria de fluorescência de raios-X por energia dispersiva (EDXRF). Ambi-Agua, Taubaté, v. 7, n. 3, p. 166-182, 2012. (http://dx.doi.org/10.4136/ambi-agua.911)

Foram realizadas três coletas, sendo os valores apresentados das médias das campanhas do dia 05/03/2011, 10/03/2011, 17/03/2011. Nesses dias, foram medidos os níveis estáticos dos poços com o auxílio de um freatímetro sonoro dotado de cabo de $100 \mathrm{~m}$. Todas as leituras foram realizadas em triplicata, buscando-se minimização de possíveis erros na manipulação da amostra.

\subsection{Método de Análise}

Após a concentração da amostra, as análises foram realizadas utilizando-se um Espectrômetro de Fluorescência de Raios-X por Energia Dispersiva (EDXRF), do modelo Shimadzu EDX-720. As seguintes condições de operação do equipamento foram selecionadas: tensão do tubo de $15 \mathrm{keV}$ ( $\mathrm{Na}$ a Sc) e $50 \mathrm{keV}$ (Ti a U) com corrente no tubo de $184 \mu \mathrm{A}$ e $25 \mu \mathrm{A}$ respectivamente, colimador de $10 \mathrm{~mm}$, tempo morto do detector de $40 \%$ e $39 \%$, sob vácuo e detector de $\mathrm{Si}(\mathrm{Li})$ refrigerado com nitrogênio líquido, (Pataca et al., 2005), com tempo real de integração de 200 segundos, tempo este diferente do usado por Pataca et al. (2005) e Wastowski et al. (2010) que utilizaram $300 \mathrm{~s}$. Wastowski et al. (2010) sugerem para corrigir os efeitos de absorção e calibrar as linhas espectrais dos elementos analisados, utilizar o padrão A750. Este padrão de calibração utilizado o qual foi fornecido junto com o Modelo EDX-720, trata-se de uma liga metálica composta por Alumínio ( $\mathrm{Al}$ ), Estanho (Sn), Magnésio $(\mathrm{Mg})$, Ferro $(\mathrm{Fe})$ e Cobre $(\mathrm{Cu})$. Desta maneira é possível determinar-se a composição do material analisado.

As amostras foram agitadas por 30 segundos buscando-se a total homogeneização, após transferiu-se $100 \mathrm{~mL}$ com o uso de pipeta volumétrica $(50 \mathrm{~mL})$ para os tubos de evaporação. As amostras foram evaporadas a uma temperatura de $70{ }^{\circ} \mathrm{C}$ em Banho Maria utilizando-se injeção de ar comprimido (25 a $30 \mathrm{lbt} \mathrm{pol}^{-2}$ ) até $1 \mathrm{~mL}$ obtendo-se uma concentração na ordem de 100 vezes, após a amostra concentrada foi transferida para um balão volumétrico de $10 \mathrm{~mL}$ e aferiuse com água destilada.

O método analítico usado é denominado método dos Parâmetros Fundamentais (FP), este método permite a obtenção da curva de sensibilidade do equipamento para cada elemento de interesse, quando uma amostra de composição química conhecida é submetida a parâmetros instrumentais bem definidos (Bona et al., 2007; Wastowski et al., 2010). A curva de sensibilidade do equipamento relaciona a intensidade fluorescente teórica calculada e a medida para cada elemento (Bona et al., 2007). Wastowski et al. (2010) afirmaram que para análises de rotina em massa, se as amostras de calibração estão ausentes, o método (FP) pode fornecer resultados relativamente precisos e quantitativos (Han et al., 2006).

Adotou-se a faixa de concentração esperada para cada constituinte avaliado nesta pesquisa sendo: Maiores os que apresentam concentrações superiores a $5 \mathrm{mg} \mathrm{L}^{-1}\left(\mathrm{Ca}^{2+}\right.$ e $\left.\mathrm{SiO}_{2}\right)$; Menores concentrações entre 0,01 até $10 \mathrm{mg} \mathrm{L}^{-1}(\mathrm{Fe})$ e; os traços com concentração inferior a $0,10 \mathrm{mg} \mathrm{L}^{-}$ ${ }^{1}$ (Cu, Zn, Ti, Mg, P) (Davies e De Wiest, 1966).

\subsection{Espacialização dos Resultados}

Para a confecção dos cartogramas, foi utilizado o programa SURFER 9 (Golden Software, 2004); como método de interpolação matemática foi utilizado krigagem (Landim e Sturaro, 2002). Logo após, foram espacializadas as informações de interesse com o uso da opção Post Map.

O cartograma da superfície potenciométrica recebeu sobreposição com o uso do comando Grid Vector Map, gerando-se, assim, uma representação do fluxo preferencial da água subterrânea (linhas de fluxo). 
KEMERICH, P. D. C.; SILVA, J. L. S.; BARROS, G.; BORBA, W. F.; UCKER, F. E.; FOLETTO, C. V. Caracterização química da água subterrânea em área ocupada por cemitério: uso da técnica de espectrometria de fluorescência de raios-X por energia dispersiva (EDXRF). Ambi-Agua, Taubaté, v. 7, n. 3, p. 166-182, 2012. (http://dx.doi.org/10.4136/ambi-agua.911)

\section{RESULTADOS E DISCUSSÃO}

A Tabela 1 ilustra aspectos relativos à flutuação dos níveis da água subterrânea (N.E.), a superfície potenciométrica (SP obtida pela relação entre a cota altimétrica na boca do poço e o nível da água no poço considerado. A tabela ilustra também as concentrações médias dos elementos analisados na área de estudo.

Tabela 1. Parâmetros dos poços de monitoramento (N.E. e S.P.) e concentrações dos elementos químicos analisados.

\begin{tabular}{|c|c|c|c|c|c|c|c|c|c|c|c|c|}
\hline Ponto & $\mathbf{N E}$ & SP & $\mathrm{Ca}^{2+}$ & $\mathrm{Cu}^{+}$ & $\mathrm{Si}^{4+}$ & $\mathbf{P}^{3+}$ & $\mathrm{Fe}^{+}$ & $\mathrm{S}^{2+}$ & $\mathbf{T i}^{2+}$ & $\mathbf{K}^{+}$ & $\mathrm{Mn}^{2+}$ & $\mathrm{Sc}^{3+}$ \\
\hline & \multicolumn{2}{|c|}{ (m) } & \multicolumn{10}{|c|}{$\left(\mathrm{mg} \mathrm{L} \mathbf{L}^{-1}\right)$} \\
\hline PM1 & 0,48 & 127,52 & 81734,80 & 3016,32 & 455896,67 & 138889,06 & 17498,55 & 100221,91 & $<$ L.D. & 12250,36 & $<$ L.D. & $<$ L.D. \\
\hline PM2 & 0,79 & 120,21 & 46557,40 & 3040,78 & 646481,40 & $<$ L.D. & 36404,71 & 99251,82 & 85,62 & 36975,83 & 47,00 & $<$ L.D. \\
\hline PM3 & 0,95 & 111,05 & 146581,81 & 2863,56 & 355535,73 & 139770,56 & 14076,23 & 101300,86 & $<$ L.D. & 6812,13 & $<$ L.D. & 271,16 \\
\hline PM4 & 0,87 & 106,13 & 178539,36 & 3122,00 & 791280,02 & 122573,97 & 159600,26 & 133147,14 & 182,92 & 71519,82 & 25,09 & $<$ L.D. \\
\hline PM5 & 0,66 & 102,34 & 129715,21 & 2826,37 & 573289,28 & 134651,98 & 5707,05 & 97124,73 & $<$ L.D. & 13346,08 & $<$ L.D. & $<$ L.D. \\
\hline PT & $*<$ L.D. & $<$ L.D. & 48565,28 & 2673,43 & $<$ L.D. & 119972,12 & $<$ L.D. & 124406,14 & $<$ L.D. & <L.D. & $<$ L.D. & $<$ L.D. \\
\hline
\end{tabular}

Nota: $*$ LD = menor do que o Limite de Detecção do aparelho Shimadzu Shimadzu EDX-720.

A Figura 2 (a) apresenta a localização dos poços de monitoramento (PM1, PM2, PM3, PM4 e PM5) e do poço tubular (PT). O poço tubular está localizado na parte mais elevada do empreendimento, em cota altimétrica $134,2 \mathrm{~m}$ e tem uma profundidade de $170 \mathrm{~m}$. Este serve no abastecimento de água para regar flores, de um morador, bem como na construção das carneiras de concreto (Garcia, 2004).

Os poços localizam-se nas cotas altimétricas (PM1) $128 \mathrm{~m}$, (PM2) em $121 \mathrm{~m}$, (PM3) em 112 m, (PM4) em 107 m e o (PM5) a 103 m. O valor médio das cotas altimétricas foi de 117,53 $\mathrm{m}$, variando de $103 \mathrm{~m}$ a $134,2 \mathrm{~m}$, sendo os maiores valores localizados a sudeste, e, representado pelos poços (PM1), (PM2) e (PT).

A Figura 2 (b) ilustra a variabilidade espacial do nível da água dos poços de monitoramento nos valores variou entre $0,48 \mathrm{~m}$ e $0,95 \mathrm{~m}$. O maior valor foi no PM3, e o menor valor no PM1, tendo-se uma média de $0,75 \mathrm{~m}$, apresentando os maiores valores a sudoeste. Estes níveis da água são bastante rasos e podem estar conflitando com o estipulado na Resolução CONAMA N³68/2006, em seu Art. 5, "I- o nível inferior das sepulturas deverá estar a uma distância de pelo menos um metro e meio acima do mais alto nível do lençol freático, medido no fim da estação das cheias. O Estado do Rio Grande do Sul não apresenta estação das cheias, que de acordo com CPRM (1994) à folha de Santa Maria, domina o clima do tipo cfa de Köppen, caracterizado como subtropical, úmido, com chuvas durante todos os meses. A precipitação média anual é de $1769 \mathrm{~mm}$ e os meses de maio, junho e setembro são os mais chuvosos, enquanto que novembro e dezembro são os mais secos.

Os valores de níveis de água subterrânea rasos = foram, também, encontrados em sete poços de monitoramento estudados por Chaves e Silvério da Silva (2008) e Chaves (2009) na cidade de Santa Maria, próximo a área deste estudo. Estes autores encontraram, dentre os poços estudados, uma variação anual da ordem de 0,25 a $3 \mathrm{~m}$, penetrando formações Cenozóicas e a Unidade Hidroestratigráfica Alemoa. 
KEMERICH, P. D. C.; SILVA, J. L. S.; BARROS, G.; BORBA, W. F.; UCKER, F. E.; FOLETTO, C. V. Caracterização química da água subterrânea em área ocupada por cemitério: uso da técnica de espectrometria de fluorescência de raios-X por energia dispersiva (EDXRF). Ambi-Agua, Taubaté, v. 7, n. 3, p. 166-182, 2012. (http://dx.doi.org/10.4136/ambi-agua.911)

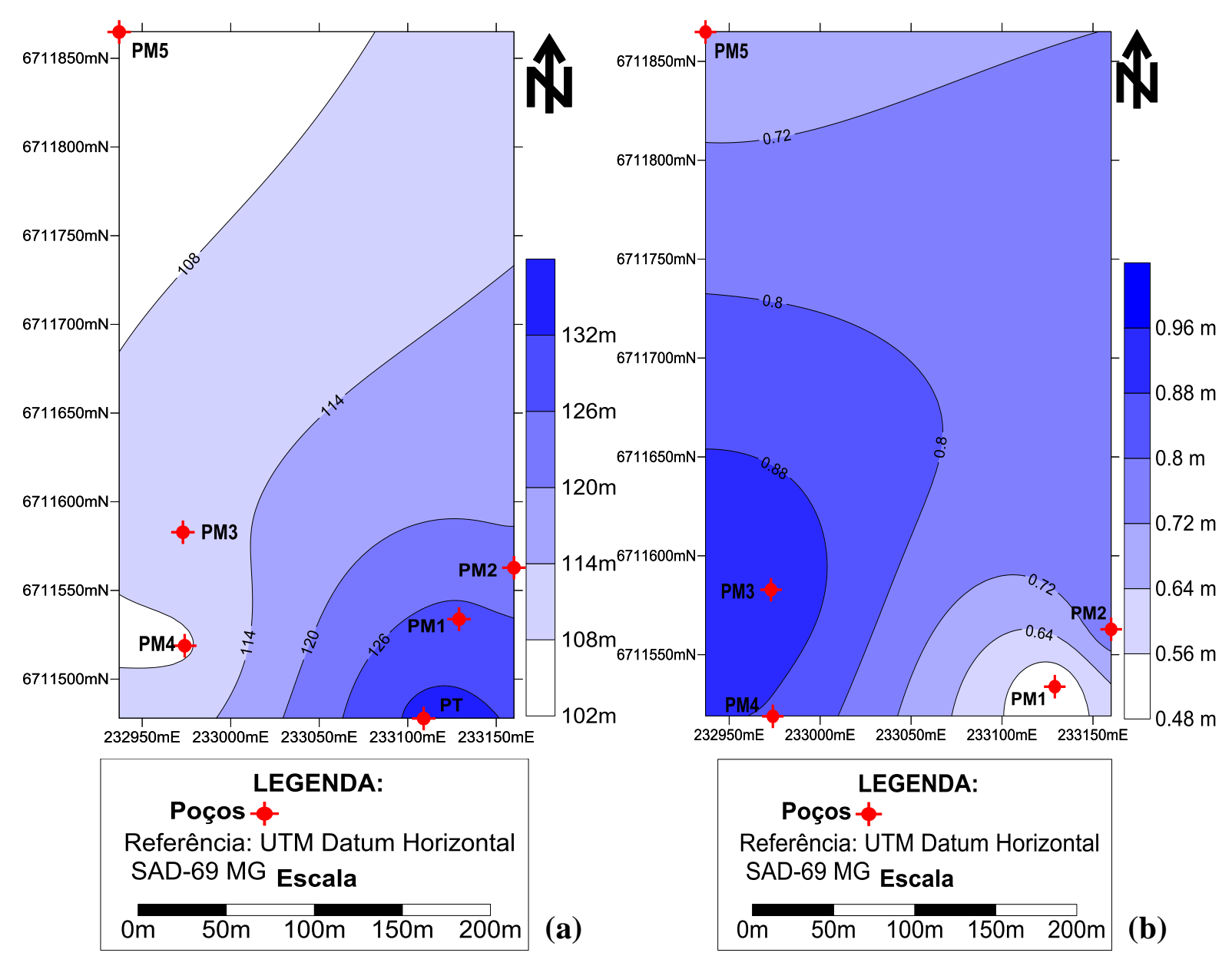

Figura 2. (a) Cartograma da localização e cota altimétrica dos poços e (b) Nível da Água dos poços.

A Figura 3 (a) ilustra a superfície potenciométrica, onde os valores variaram entre 102,3 a 127,5 m próximo da Rodovia Estadual RS-509. Os maiores valores ocorreram na porção sudeste do cemitério (PM1 e PM2), tendo-se uma média entre os poços de 113,4 $\pm 10,3 \mathrm{~m}$. Estima-se que os poços localizados nas cotas altimétricas mais baixas, estiveram sob maior influência do fluxo subterrâneo de direção Sul para Norte e Noroeste. Podendo ter influenciado nas concentrações dos constituintes maiores $\left(\mathrm{Ca}^{2+}\right)$ e $\left(\mathrm{SiO}_{2}\right)$, menores $(\mathrm{Fe})$ e os traços analisados.

Os valores de concentração cálcio $\left(\mathrm{Ca}^{2+}\right)$ variaram entre $4,65 \mathrm{mg} \mathrm{L}^{-1}$ e $17,85 \mathrm{mg} \mathrm{L}^{-1}$ de $\mathrm{Ca}^{2+}$, o valor médio foi de $10,53 \pm 5,46 \mathrm{mg} \mathrm{L}^{-1}$. Os maiores valores de concentração encontrados localizam-se à sudoeste, tendo maior valor no poço PM3, como mostra a Figura 3 (b).

O cálcio é um elemento maior na maioria das águas e na crosta terrestre. É comum precipitar-se como carbonato de cálcio $\left(\mathrm{CaCO}_{3}\right)$ em água com o $\mathrm{pH}$ maior ou igual a 8,2. Comumente apresenta-se sob a forma de bicarbonato $\left(\mathrm{HCO}_{3}{ }^{-}\right)$. A solubilidade do bicarbonato de cálcio aumenta na presença de sais de Sódio $\left(\mathrm{Na}^{+}\right)$e Potássio $\left(\mathrm{K}^{+}\right)$(Mestrinho, 2008).

Verificou-se que tanto a Organização Mundial da Saúde, quanto a Portaria No 518/2004 do Ministério da Saúde, bem como a Resolução No 396/2008, não fazem referência à concentração de cálcio isoladamente, mas este elemento aparece associado à dureza total da água. Alguns autores como Feitosa e Manoel Filho (1997) apresentam a faixa de variação para as águas subterrâneas naturais, com teores variando entre 10 e $100 \mathrm{mg} \mathrm{L}^{-1}$. 
KEMERICH, P. D. C.; SILVA, J. L. S.; BARROS, G.; BORBA, W. F.; UCKER, F. E.; FOLETTO, C. V. Caracterização química da água subterrânea em área ocupada por cemitério: uso da técnica de espectrometria de fluorescência de raios-X por energia dispersiva (EDXRF). Ambi-Agua, Taubaté, v. 7, n. 3, p. 166-182, 2012. (http://dx.doi.org/10.4136/ambi-agua.911)

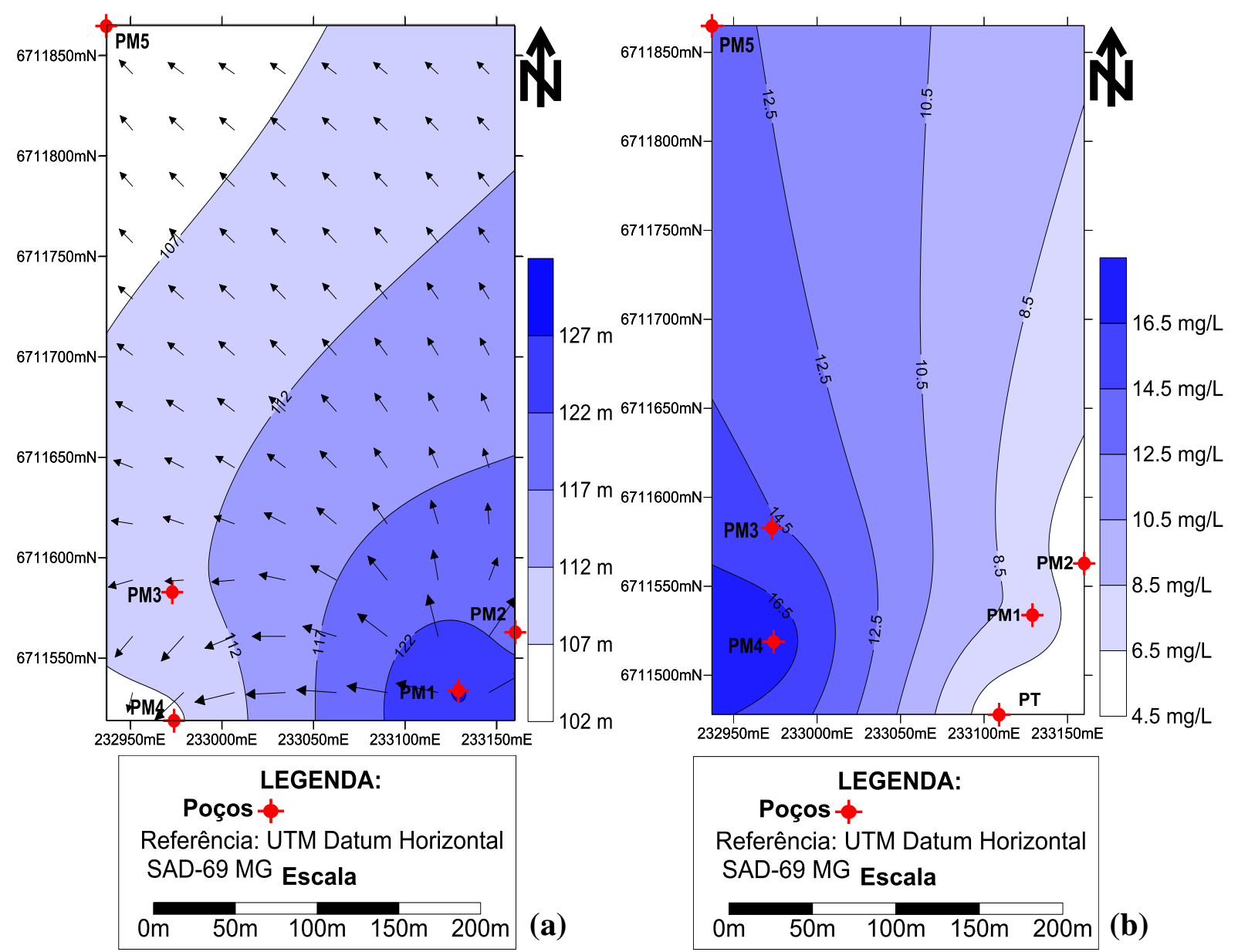

Figura 3. (a) Cartograma da superfície potenciométrica e (b) Concentração de Cálcio na água dos poços.

Kemerich (2008) e Kemerich et al. (2011) relataram em estudo sobre a qualidade da água subterrânea no Bairro Nossa Senhora do Perpétuo Socorro no Município de Santa Maria-RS situado em zona de afloramento do Sistema Aquífero Guarani/SAG. Analisaram cerca de 54 amostras de captações através de poços tubulares, escavados de grande diâmetros e nascentes. Destes, apenas $22,72 \%$ situaram-se entre concentrações 10 e $100 \mathrm{mg} \mathrm{L}^{-1} \mathrm{de} \mathrm{Ca}^{2+}$, sendo que apenas um poço escavado ultrapassou os $100 \mathrm{mg} \mathrm{L}^{-1}$, tendo como valor determinado $241 \mathrm{mg} \mathrm{L}^{-}$ ${ }^{1}$, associado a um $\mathrm{pH}$ do meio levemente ácido de 6,8 .

Os valores de silício variaram entre $35,55 \mathrm{mg} \mathrm{L}^{-1}$ no poço (PM4) e 79,51 $\mathrm{mg} \mathrm{L}^{-1}$ (PM3), tendo-se como valor médio de $56,45 \mathrm{mg} \mathrm{L}^{-1}$. Não foi detectada silício na amostra proveniente do poço Tubular (PT). A Figura 4 (a) ilustra a distribuição das concentrações de silício nos poços amostrados. Silvério da Silva et al. (2006) encontraram valores de concentração da ordem 25 a $98,19 \mathrm{mg} \mathrm{L}^{-1}$ estudando cerca de 22 captações de águas subterrâneas em poços de abastecimento do SAG na fronteira do Brasil e do Uruguai. Na água do Rio Quarai foi obtida uma concentração de $27,95 \mathrm{mg} \mathrm{L}^{-1}$.

Os valores de Ferro variaram entre 0,57 e $15,96 \mathrm{mg} \mathrm{L}^{-1}$, com valor médio 4,67 $\pm 6,41 \mathrm{mg}$ $\mathrm{L}^{-1}$, sendo que os maiores valores apresentaram-se à sudoeste (PM3) conforme ilustrado na Figura 4 (b). 
KEMERICH, P. D. C.; SILVA, J. L. S.; BARROS, G.; BORBA, W. F.; UCKER, F. E.; FOLETTO, C. V. Caracterização química da água subterrânea em área ocupada por cemitério: uso da técnica de espectrometria de fluorescência de raios-X por energia dispersiva (EDXRF). Ambi-Agua, Taubaté, v. 7, n. 3, p. 166-182, 2012. (http://dx.doi.org/10.4136/ambi-agua.911)

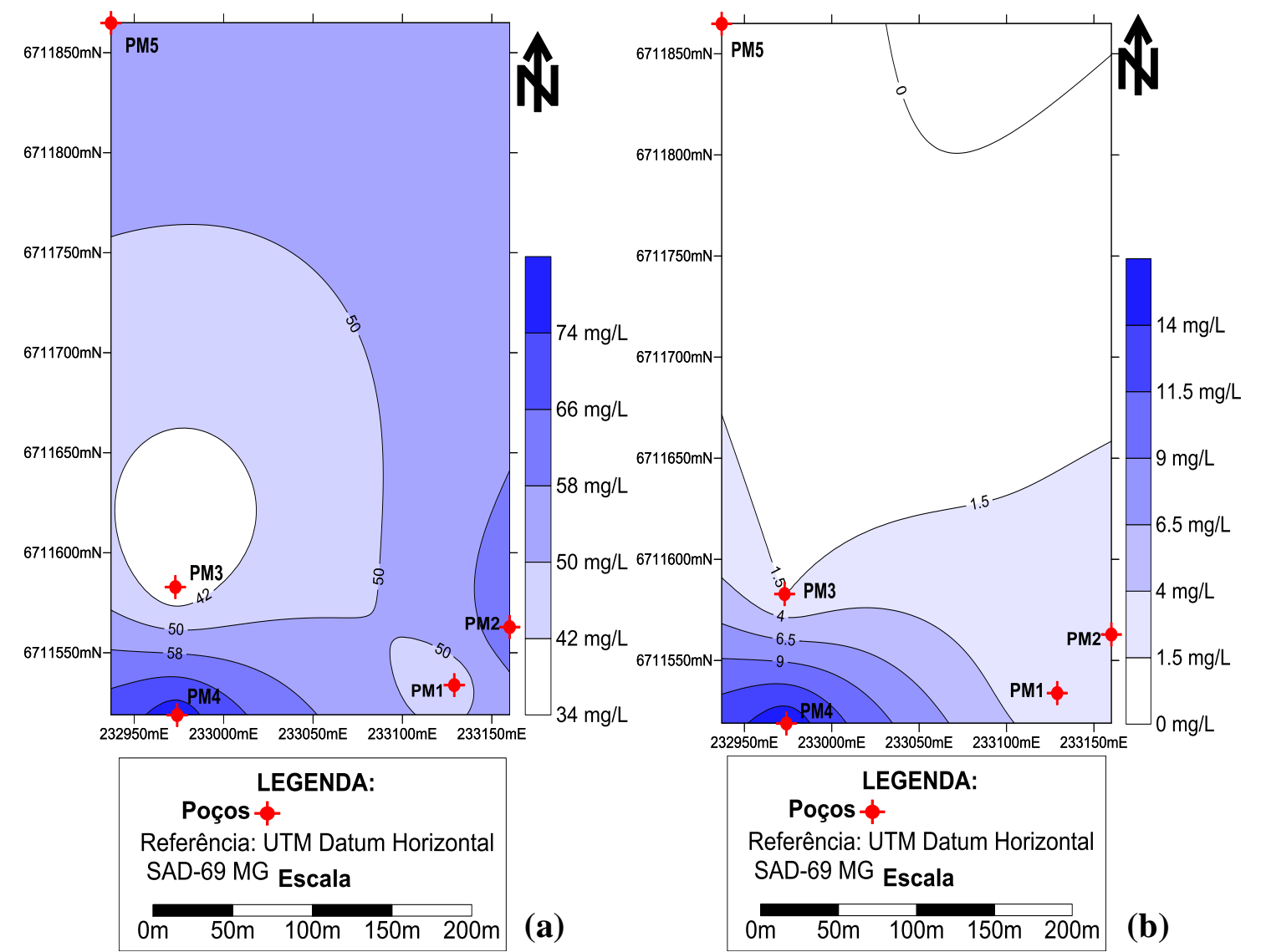

Figura 4. (a) Cartograma da concentração de Silício (Si) e (b) Ferro $\left(\mathrm{Fe}^{2+}\right)$ na água dos poços.

O Ferro é um elemento persistentemente presente em quase todas as águas subterrâneas em teores abaixo de $0,3 \mathrm{mg} \mathrm{L}^{-1}$. Águas com alto conteúdo de Fe, ao saírem da captação por poços são incolores, mas ao entrarem em contato com o oxigênio do ar tornam-se amareladas, o que lhes confere uma aparência nada agradável. Este fenômeno natural ocorre em algumas captações na região de Santa Maria, em zona de afloramento do SAG.

O Ferro, como um importante constituinte das águas subterrâneas, tem origem, principalmente, em compostos minerais tais como os aluminosilicatos (piroxênios, anfibólios, biotita) e/o sulfetos, como a pirita (Davies e De Wiest, 1991; Lemes et al., 2003). Uma água subterrânea onde os níveis de Ferro são elevados, numa primeira avaliação, pode ser preterida a outras águas, até contaminadas com coliformes, em função da cor e do gosto desagradável em decorrência da presença do elemento (Unesco et al., 1992).

A Figura 5 (a) apresenta as concentrações de cobre na água subterrânea coletada nos poços de monitoramento e poço Tubular (PT). O poço PM3 apresentou a maior concentração de $\mathrm{Cu}$, e o menor valor detectado pertence ao poço tubular $0,31,0,26$ e $0,26 \mathrm{mg} \mathrm{L}^{-1}$ respectivamente. Este apresenta um pH alcalino de 8,0, com uma Condutividade Elétrica de cerca de $180 \mu \mathrm{S} \mathrm{cm}^{-}$ ${ }^{1}$ e um concentração de Sólidos Totais Dissolvidos (STD) de cerca de $117 \mathrm{mg} \mathrm{L}^{-1}$, portanto uma água doce (Fachin, 2005).

A média das concentrações foi de $0,29 \pm 0,02 \mathrm{mg} \mathrm{L}^{-1}$, observando-se que os valores de concentração do Cobre da água de todos os poços são muito semelhantes, com valores destaque a valores maiores na porção centro sul do cartograma (Figura 5a).

Todos os poços apresentaram os valores de concentração abaixo das normas brasileiras, sendo que a Portaria do Ministério da Saúde No 518/2004 fixou o Padrão de potabilidade para 
KEMERICH, P. D. C.; SILVA, J. L. S.; BARROS, G.; BORBA, W. F.; UCKER, F. E.; FOLETTO, C. V. Caracterização química da água subterrânea em área ocupada por cemitério: uso da técnica de espectrometria de fluorescência de raios-X por energia dispersiva (EDXRF). Ambi-Agua, Taubaté, v. 7, n. 3, p. 166-182, 2012. (http://dx.doi.org/10.4136/ambi-agua.911)

substâncias químicas que representam risco à saúde como Valor Máximo Permissível - VMP para Cobre $2 \mathrm{mg} \mathrm{L}^{-1}$, o que evidencia os baixos valores encontrados nesta pesquisa.

Davies e De Wiest (1991) encontraram amostras com concentrações de Cobre e com valor máximo de $0,044 \mathrm{mg} \mathrm{L}^{-1}$. Tais valores ficam abaixo dos encontrados, podendo indicar aumento em função de características distintas dos dois locais de estudo ou até mesmo aumento na concentração em função da presença do cemitério.

Os valores de fósforo nas amostras de água subterrânea variaram entre 11,97 e $13,98 \mathrm{mg} \mathrm{L}^{-1}$, com valor médio de $13,26 \mathrm{mg} \mathrm{L}^{-1}$ (Figura $5 \mathrm{~b}$ ). O maior valor encontrado foi na amostra proveniente do poço PM4 (13,98 $\left.\mathrm{mg} \mathrm{L}^{-1}\right)$. A Figura 6 (a) ilustra a espacialização das concentrações de fosfato na água dos poços na região do cemitério. Destacando-se que as maiores concentrações ocorreram nas regiões sudoeste e norte do cartograma.

A forma constituinte responsável pelo fósforo são os sólidos em suspensão e dissolvidos, e sua origem natural é pela dissolução de compostos do solo e da matéria orgânica (Botelho, 2001). O fosfato é um elemento fundamental para o metabolismo dos seres vivos e sua presença em águas naturais depende das características das rochas da região.

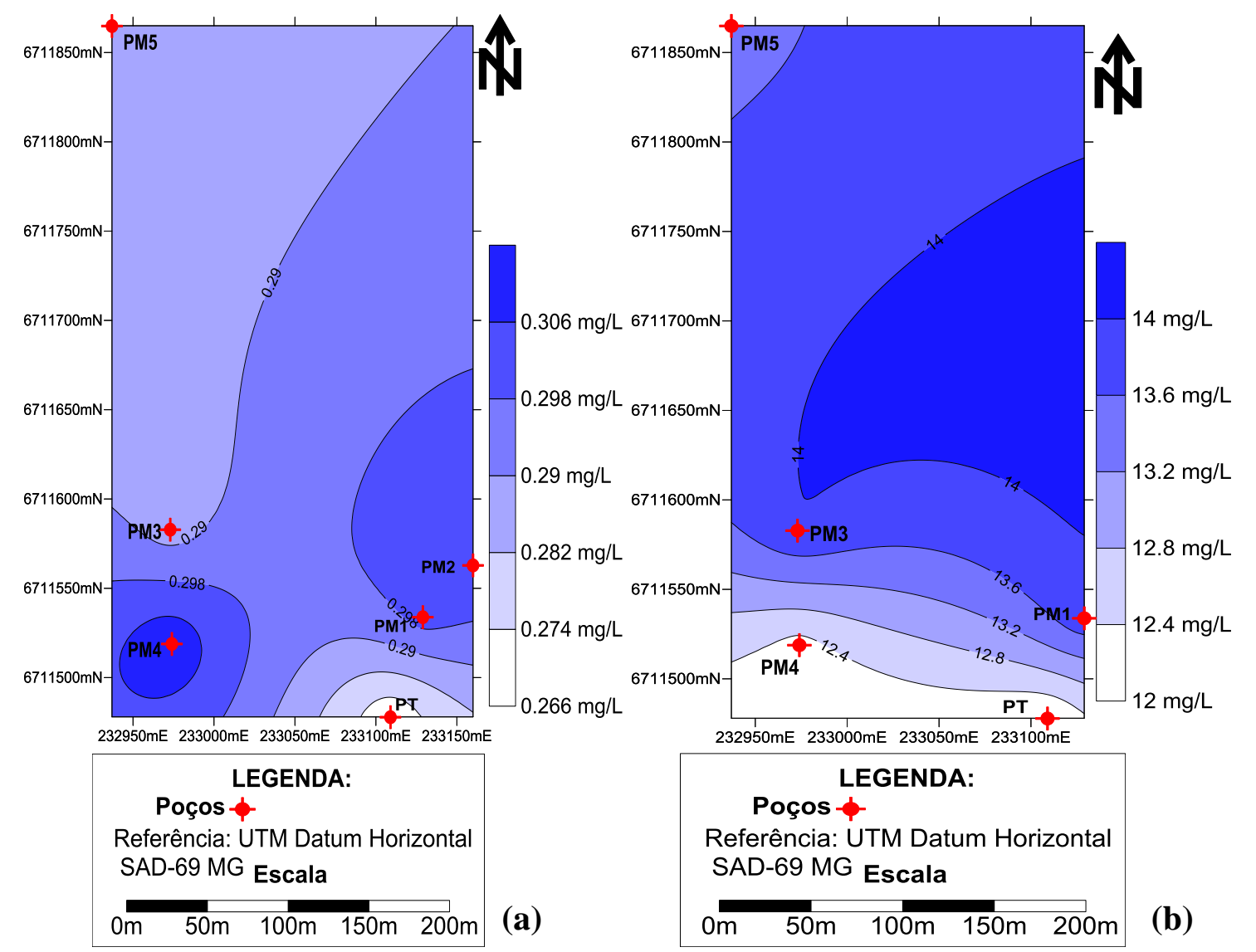

Figura 5. (a) Cartograma da concentração de Cobre $\left(\mathrm{Cu}^{+}\right)$e (b) Fósforo na água dos Poços.

O potássio é um dos dez elementos químicos mais abundantes na crosta terrestre, mas ocorre em pequena quantidade nas águas subterrâneas, pois é facilmente fixado pelos argilominerais e como elemento essencial, é intensivamente consumido pelos vegetais. Seus principais minerais fontes são: Feldspato potássico e a biotita, pouco resistentes aos intemperismo físico e químico. Outra fonte são as micas muscovitas. Este elemento é comum nos argilominerais do tipo Ilitas e interesetraficados I/S comuns na Unidade Hidroestratigráfica Alemoa (Silvério da Silva et al., 2010). Nas águas subterrâneas seu teor médio é inferior a 
KEMERICH, P. D. C.; SILVA, J. L. S.; BARROS, G.; BORBA, W. F.; UCKER, F. E.; FOLETTO, C. V. Caracterização química da água subterrânea em área ocupada por cemitério: uso da técnica de espectrometria de fluorescência de raios-X por energia dispersiva (EDXRF). Ambi-Agua, Taubaté, v. 7, n. 3, p. 166-182, 2012. (http://dx.doi.org/10.4136/ambi-agua.911)

$10 \mathrm{mg} \mathrm{L}^{-1}$. Silvério da Silva et al. (2006) relataram valores entre 0,31 a $3,43 \mathrm{mg} \mathrm{L}^{-1}$, e um valor médio de $1,42 \mathrm{mg} \mathrm{L}^{-1}$, na água do Rio Quarai encontraram $0,78 \mathrm{mg} \mathrm{L}^{-1}$.

Conforme ilustrado na Figura 6, os valores de concentração do potássio variaram de 0,50 a $7 \mathrm{mg} \mathrm{L}{ }^{-1}$. Observa-se que as concentrações mais elevadas ocorreram no setor sul da área estudada. Kemerich (2009) e Kemerich et al. (2011) estudando a qualidade da água subterrânea no Bairro Nossa Senhora do Perpétuo Socorro em Santa Maria - RS encontraram valores entre 0,10 a $11 \mathrm{mg} \mathrm{L}^{-1}$.

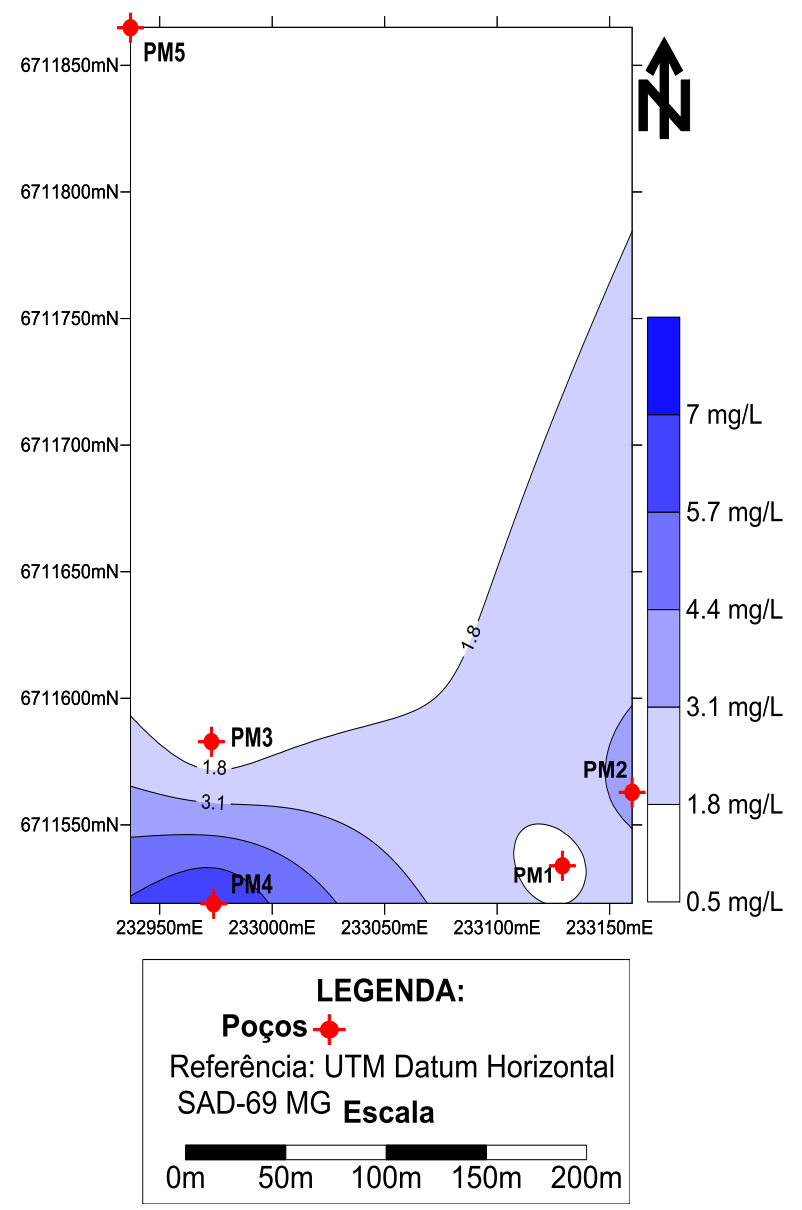

Figura 6. Cartograma da concentração Potássio $\left(\mathrm{K}^{+}\right)$na água dos poços.

A Técnica de Espectrometria de Fluorescência de Raios - X por Energia Dispersiva apresentou resultados extremamente baixos para as concentrações dos elementos de transição avaliados: Titânio, Manganês e Escândio (Tabela 2). Em alguns poços as amostras de água subterrânea não tiveram os elementos detectados pelo equipamento. Hem (1985) relata que os metais de transição geralmente apresentam mais do que um estado de oxidação que é estável termodinamicamente em presença da água. Vários destes elementos estão relacionados na água na forma de complexos aniônicos em $\mathrm{pH}$ neutro.

Krieger (2000) apresentou resultados para o parâmetro de Manganês dissolvido, que variaram na faixa de 11 a 45,6 $\mathrm{mg} \mathrm{L}^{-1}$. O comportamento do $\mathrm{Fe}$ e do $\mathrm{Mn}$, que apresentam dois números de oxidação, é controlado pelos fenômenos de oxidação-redução, que são especialmente importantes em relação a sua solubilidade (Hem, 1985; Mestrinho, 2008). Aqui se deve lembrar que a zona saturada e insaturada do subsolo altera-se durante o ano e pode influenciar diretamente número de oxidação do $\mathrm{Fe}$ e Mn, além do pH do meio. 
KEMERICH, P. D. C.; SILVA, J. L. S.; BARROS, G.; BORBA, W. F.; UCKER, F. E.; FOLETTO, C. V. Caracterização química da água subterrânea em área ocupada por cemitério: uso da técnica de espectrometria de fluorescência de raios-X por energia dispersiva (EDXRF). Ambi-Agua, Taubaté, v. 7, n. 3, p. 166-182, 2012. (http://dx.doi.org/10.4136/ambi-agua.911)

O Manganês $\left(\mathrm{Mn}^{2+}\right)$ é um elemento que acompanha o Ferro em virtude de seu comportamento geoquímico. Ocorre em teores abaixo de $0,20 \mathrm{mg} \mathrm{L}^{-1}$, quase sempre como óxido de manganês bivalente, que se oxida em presença do ar atmosférico, dando origem a precipitados negros.

Dos três elementos metais traços, apenas o $\left(\mathrm{Mn}^{2+}\right)$ tem fixado o VMP de $0,10 \mathrm{mg} \mathrm{L}^{-1}$ Resolução CONAMA No 396/2008 e Portaria No 518/2004 do Ministério da Saúde (Brasil, 2004), sendo que nenhuma das amostras avaliadas superou o VMP. A Resolução CONAMA N ${ }^{\circ}$ 420/2009 indica para valor de investigação $1,05 \mathrm{mg} \mathrm{L}^{-1}$.

Tabela 2. Concentrações de Titânio, Manganês e Escândio nos poços de monitoramento.

\begin{tabular}{c|ccc}
\hline $\begin{array}{c}\text { Poço de } \\
\text { Monitoramento }\end{array}$ & Titânio $\left(\mathbf{T i}^{\mathbf{2 +}}\right)$ & Manganês $\left(\mathbf{M n}^{2+}\right)$ & Escândio $\left(\mathbf{S c}^{\mathbf{3 +}}\right)$ \\
\cline { 2 - 4 } & & $\left(\mathbf{m g ~ L} \mathbf{~ L}^{\mathbf{1}}\right)$ & \\
\hline 1 & 0,009 & 0,005 & $*<$ L.D. \\
2 & <L.D. & $<$ L.D. & $<$ L.D. \\
3 & 0,018 & 0,003 & $<$ L.D. \\
4 & <L.D. & $<$ L.D. & 0,027 \\
5 & <L.D. & <L.D. & $<$ L.D. \\
6 & <L.D. & <L.D. & $<$ L.D. \\
\hline
\end{tabular}

Nota: $*<$ L.D. $=$ menor do que o Limite de Detecção do aparelho Shimadzu Shimadzu EDX-720.

A Tabela 3 ilustra correlação entre os parâmetros analisados, sendo que os valores destacados na cor vermelha apresentaram correlação.

Apresentaram correlação a Superfície Potenciométrica (S.P.) e a Altitude (1), o elemento Enxofre e Ferro $(0,98)$. O elemento Titânio apresentou correlação com os elementos Silício $(0,89)$ e Ferro $(0,95)$. O Cálcio apresentou correlação com Silício $(0,92)$ e Ferro $(0,95)$.

Estas correlações podem indicar que são provenientes da mesma fonte geradora, porém nenhum elemento apresentou correlação com o fluxo de água subterrânea.

Tabela 3. Matriz de correlação dos elementos químicos estudados e características físicas do local em estudo.

\begin{tabular}{|c|c|c|c|c|c|c|c|c|c|c|c|c|c|}
\hline & Alt.(m) & NE (m) & $\mathbf{S P}(\mathbf{m})$ & $\mathrm{Ca}^{2+}$ & $\mathrm{Cu}^{+}$ & $\mathrm{Si}^{4+}$ & $\mathbf{P}^{3+}$ & $\mathrm{Fe}^{+}$ & $\mathrm{S}^{2+}$ & $\mathrm{Ti}^{2+}$ & $\mathbf{K}^{+}$ & $\mathrm{Mn}^{2+}$ & $\mathrm{Sc}^{3+}$ \\
\hline Alt.(m) & 1 & & & & & & & & & & & & \\
\hline NE (m) & $-0,5$ & 1 & & & & & & & & & & & \\
\hline SP (m) & $1^{*}$ & $-0,51$ & 1 & & & & & & & & & & \\
\hline $\mathrm{Ca}^{2+}$ & $-0,75$ & 0,49 & $-0,75$ & 1 & & & & & & & & & \\
\hline $\mathrm{Cu}^{+}$ & 0,37 & 0 & 0,36 & $-0,09$ & 1 & & & & & & & & \\
\hline $\mathrm{Si}^{4+}$ & $-0,32$ & 0,14 & $-0,32$ & 0,17 & 0,67 & 1 & & & & & & & \\
\hline $\mathbf{P}^{3+}$ & $-0,32$ & $-0,16$ & $-0,31$ & 0,69 & $-0,37$ & $-0,38$ & 1 & & & & & & \\
\hline $\mathrm{Fe}^{+}$ & $-0,29$ & 0,38 & $-0,29$ & 0,54 & 0,76 & 0,8 & $-0,02$ & 1 & & & & & \\
\hline$S^{2+}$ & $-0,34$ & 0,39 & $-0,35$ & 0,66 & 0,68 & 0,7 & 0,15 & $0,98^{*}$ & $1^{*}$ & & & & \\
\hline $\mathbf{T i}^{2+}$ & $-0,22$ & 0,42 & $-0,23$ & 0,31 & 0,81 & $0,89 *$ & $-0,32$ & $0,95^{*}$ & 0,88 & 1 & & & \\
\hline $\mathbf{K}^{+}$ & $-0,24$ & 0,35 & $-0,24$ & 0,32 & 0,81 & $0,92 *$ & $-0,29$ & $0,95^{*}$ & 0,89 & 1 & 1 & & \\
\hline $\mathrm{Mn}^{2+}$ & 0,16 & 0,31 & 0,15 & $-0,39$ & 0,65 & 0,67 & $-0,91$ & 0,43 & 0,27 & 0,69 & 0,66 & 1 & \\
\hline $\mathrm{Sc}^{3+}$ & $-0,12$ & 0,6 & $-0,13$ & 0,32 & $-0,49$ & $-0,69$ & 0,3 & $-0,28$ & $-0,18$ & $-0,37$ & $-0,44$ & $-0,38$ & 1 \\
\hline
\end{tabular}

Nota: Destacadas em vermelho, as correlações significativas para $\mathrm{p}<, 050$. 
KEMERICH, P. D. C.; SILVA, J. L. S.; BARROS, G.; BORBA, W. F.; UCKER, F. E.; FOLETTO, C. V. Caracterização química da água subterrânea em área ocupada por cemitério: uso da técnica de espectrometria de fluorescência de raios-X por energia dispersiva (EDXRF). Ambi-Agua, Taubaté, v. 7, n. 3, p. 166-182, 2012. (http://dx.doi.org/10.4136/ambi-agua.911)

\section{CONCLUSÃO}

A técnica de Espectrometria Fluorescência de Raios - $\mathrm{X}$ por energia dispersiva demonstrou ser rápida e eficiente para quantificação de vários constituintes em águas subterrâneas sob a influência de cemitério apresentando uma potencial aplicação para o monitoramento ambiental semiquantitativo-qualitativo.

Utilizando-se a técnica EDXRF foi possível determinar as concentrações dos constituintes: maiores $\left(\mathrm{Ca}^{2+}\right.$, silício), menores $\left(\mathrm{Fe}^{+}\right)$e traços $\left(\mathrm{K}^{+}, \mathrm{Cu}^{+}\right.$, fósforo, $\mathrm{Ti}^{+}, \mathrm{Mn}^{+}$e $\mathrm{Sc}^{+}$, facilitando a caracterização química das águas subterrâneas bem como as comparações aos padrões das legislações ambientais vigentes. Estudos futuros em águas subterrâneas comprovarão a eficácia da técnica.

Estimou-se que alguns elementos tiveram seus valores acrescidos em função do fluxo subterrâneo, evidenciando uma possível relação entre a presença de sepulturas e a alteração da qualidade natural da água subterrânea indicando uma poluição difusa, pontual, por substâncias oriundas de processos de alteração caixões, ornamentos mortuários e corpos humanos.

Salienta-se que o terreno apresenta textura silto-argilosa e os argilominerais apresentam elevada capacidade de troca, o que pode ser eficiente na adsorção dos constituintes maiores, menores e traços, na forma catiônica associados ao ambiente de características oxidantes, pelo menos no período de verão.

\section{REFERÊNCIAS}

ASSOCIAÇÃO BRASILEIRA DE NORMAS TÉCNICAS. NBR 15.495: poços de monitoramento de águas subterrâneas em aqüíferos granulados. Rio de Janeiro, 2007.

BOTELHO, C. G. Recursos naturais renováveis e impacto ambiental. Lavras: UFLA/FAEPE, 2001. $136 \mathrm{p}$.

BÖGER, H.; KOWALCZYK, G. Stratigraphische, sedimentologische und Paläoökologische Untersuchungen Im Mesozoikum Der Depressão Periférica in Rio Grande do Sul, Brasilien. Geologisch-Paläontologisches Institut und Museum, Universität Kiel, Berichte-Reports, n. 63, p. 1-72, 2003.

BONA, I. A. T.; SARKIS, J. E. S.; SALVADOR, V. L. R.; SOARES, A. L. R.; KLAMT, S. L. Análise arqueométrica de cerâmica Tupiguarani da região central do Estado do Rio Grande do Sul, Brasil, usando fluorescência de raios X por dispersão de energia (EDXRF). Química Nova, São Paulo, n. 30, p. 785-790, jan./fev. 2007. http://dx.doi.org/10.1590/S0100-40422007000400006

BRASIL. Ministério da Saúde. Portaria $\mathbf{N}^{\circ}$ 518, de 25 de março de 2004. Estabelece os procedimentos e responsabilidades relativos ao controle e vigilância da qualidade da água para consumo humano e seu padrão de potabilidade, e dá outras providências. Brasília, 2004. Disponível em: <http://portal.saude.gov.br/portal/arquivos/ pdf/portaria_518.pdf>. Acesso em: 03 mar. 2011.

CHAVES, A.; SILVÉRIO Da SILVA, J. L. Comportamento do fluxo das águas subterrâneas na área de um empreendimento potencialmente poluidor no Município de Santa Maria. In: CONGRESSO BRASILEIRO DE ÁGUAS SUBTERRÂNEAS, 15., 11 - 14 nov. 2008, Natal. Comunicação Apresentada no... Natal: ABAS, 2008. p. 1-16. 
KEMERICH, P. D. C.; SILVA, J. L. S.; BARROS, G.; BORBA, W. F.; UCKER, F. E.; FOLETTO, C. V. Caracterização química da água subterrânea em área ocupada por cemitério: uso da técnica de espectrometria de fluorescência de raios-X por energia dispersiva (EDXRF). Ambi-Agua, Taubaté, v. 7, n. 3, p. 166-182, 2012. (http://dx.doi.org/10.4136/ambi-agua.911)

CHAVES, A. Monitoramento de águas subterrâneas em um empreendimento potencialmente poluidor no Município de Santa Maria/RS. 2009. 187f. Dissertação (Mestrado em Engenharia Civil/Recursos Hídricos e Saneamento Ambiental) Universidade Federal de Santa Maria, Santa Maria, 2009.

CONSELHO NACIONAL DE MEIO AMBIENTE (Brasil). Resolução $\mathbf{N}^{\mathbf{0}} \mathbf{3 3 5}$, de 3 de abril de 2003. Dispõe sobre o licenciamento ambiental de cemitérios. Brasília, 2003. Disponível em: <http://www.mma.gov.br/port/conama/res/res03/res33503.xml>. Acesso em: 3 mar. 2011.

CONSElHO NACIONAL DE MEIO AMBIENTE. (Brasil) Resolução $\mathbf{N}^{\mathbf{0}} \mathbf{3 6 8}$, de 28 de março de 2006. Altera dispositivos da Resolucção $n^{\circ} 335$, de 3 de abril de 2003, que dispõe sobre o licenciamento ambiental de cemitérios. Brasília, 2006. Disponível em: <http://www.mma.gov.br/port/conama/legiabre.cfm?codlegi=488>. Acesso em: 3 mar. 2011.

CONSELHO NACIONAL DO MEIO AMBIENTE. (Brasil). Resolução No 396, de 03 de abril de 2008. Dispõe sobre a classificação e diretrizes ambientais para o enquadramento das águas subterrâneas e dá outras providências. Brasília, 2008. Disponível em: <http://www.mma.gov.br/port/conama/legiabre.cfm?codlegi=562>. Acesso em: 02 mar. 2011.

CONSELHO NACIONAL DO MEIO AMBIENTE. (Brasil). Resolução No 420, de 28 de Dezembro de 2009. Dispõe sobre critérios e valores orientadores de qualidade do solo quanto à presença de substâncias químicas e estabelece diretrizes para o gerenciamento ambiental de áreas contaminadas por essas substâncias em decorrência de atividades antrópicas. Brasília, 2009. Disponível em: <http://www.mp.rs.gov.br/ambiente/ legislacao/id4830.htm>. Acesso em: 22 out. 2012.

DAVIES, S. N.; De WIEST, R. J. M. Hydrogeology. New York: John Wiley and Sons, 1966. $463 p$.

DAVIES, S. N.; De WIEST, R. J. M. Hydrogeology. Flórida: Krieger Publishing Company, 1991.

FACHIN, E. F. Distribuição espacial dos poços tubulares profundos e informações físicoquímicas das águas subterrâneas no município de Santa Maria/RS. 2003. 72f. Trabalho de Conclusão de Curso (Graduação) - Universidade Federal de Santa Maria, Santa Maria, 2003.

FACHIN, E. F. Avaliação da vulnerabilidade natural dos aquíferos em Santa Maria/RS. 2005. 91f. Monografia (Especialização em Geociências) - Universidade Federal de Santa Maria, Santa Maria, 2005.

FEITOSA, A C. F.; MANOEL FILHO, J. Hidrogeologia: conceitos e aplicações. Fortaleza: LCR, 1997. 812 p.

GARCIA, G. P. Avaliação de pontos potenciais de contaminação de águas subterrâneas em Santa Maria, RS. 2004. 60f. Trabalho de Conclusão de Curso (Graduação em Geografia) - Universidade Federal de Santa Maria, Santa Maria, 2004. 
KEMERICH, P. D. C.; SILVA, J. L. S.; BARROS, G.; BORBA, W. F.; UCKER, F. E.; FOLETTO, C. V. Caracterização química da água subterrânea em área ocupada por cemitério: uso da técnica de espectrometria de fluorescência de raios-X por energia dispersiva (EDXRF). Ambi-Agua, Taubaté, v. 7, n. 3, p. 166-182, 2012. (http://dx.doi.org/10.4136/ambi-agua.911)

GASPARETTO, N. V. L.; MEDEIROS, E. R.; VIEIRA, P.; MACIEL FILHO, C. L.; SARTORI, P. L. P.; MENEGOTTO, E. Mapa geológico da folha de Santa Maria e nota explicativa. Santa Maria: FINEP; UFSM, 1990. 1 Mapa. Escala 1:50.000.

GOLDEN SOFTWARE, Inc. Surfer 8.0: contouring and 3D surface mapping for scientists and engineers: user's guide. Golden, 2004. 640 p.

HAN, X. Y.; ZHUO, S. J.; SHEN, R. X.; WANG, P. L.; JI, A. Comparison of the quantitative results corrected by fundamental parameter method and difference calibration specimens in x-ray fluorescence spectrometry. Journal of Quantitative Spectroscopy and Radiative Transfer, v. 97, n. 1, p. 68-74, 2006. http://dx.doi.org/10.1016/ j.jqsrt.2004.12.018

HEM, J. D. Study and interpretation of the chemical characteristics of natural water. Alexandria: USGS, 1985. 267 p.

KEMERICH, P. D. C. Água subterrânea e a saúde da comunidade em Bairro de Santa Maria- RS. 2008. 108f. Dissertação (Mestrado Recursos Hídricos e Saneamento Ambiental) - Universidade Federal de Santa Maria, Santa Maria, 2008.

KEMERICH, P. D. C.; SILVÉRIO da SILVA, J. L.; DESCOVI FILHO, L. L. V.; VOLPATTO, F.; SAUCEDO, E. M. Determinação da vulnerabilidade natural à contaminação da água subterrânea no Bairro Nossa Senhora do Perpétuo Socorro em Santa Maria, RS. Engenharia Ambiental, Espírito Santo do Pinhal, v. 8, n.3, p. 85-98, jul. /set. 2011.

KEMERICH, P. D. C.; UCKER, F. E.; BORBA, W. F. Cemitérios como fonte de contaminação ambiental. Scientific American Brasil, São Paulo, n. 123, p 78-81, ago. 2012. Disponível em: <http://www2.uol.com.br/sciam/artigos/cemiterios_como_fonte_ de_contaminacao_ambiental.html> Acesso em: 22 out. 2012.

KRIEGER, E. I. F. Avaliação da contaminação das águas subterrâneas na área de influência da usina de tratamento de resíduos S/A - UTRESA, em Estância Velha (RS). 2000. 148f. Dissertação (Mestrado em Biociências) - Universidade Federal do Rio Grande do Sul, Porto Alegre, 2000.

LANDIM, P. M. B.; STURARO, J. R. Krigagem indicativa aplicada à elaboração de mapas probabilísticos de riscos. Rio Claro: DGA;IGCE;UNESP, 2002. 253 p.

LEMES, M. J. DE L.; FIGUEIREDO FILHO, P. M.; PIRES, M. A. F. Mineral influence on chemical composition of drinking water supply from Mogi-Guaçu and Pardo rivers. Química Nova, São Paulo, v. 26, n. 1, p. 13-20, jan./fev. 2003. http://dx.doi.org/10.1590/S0100-40422003000100004.

MACIEL FILHO, C. L. Carta geotécnica de Santa Maria. Santa Maria: Imprensa Universitária UFSM, 1990.

MACHADO, J. L. F. Compartimentação espacial e arcabouço hidroestratigráfico do SAG no Rio Grande do Sul. 2005. 237f. Tese (Doutorado em Geologia) - Universidade do Vale dos Sinos, Porto Alegre, 2005.

MESTRINHO, S. S. Hidrogeologia, conceitos e aplicações. Brasília: CPRM, 2008. 
KEMERICH, P. D. C.; SILVA, J. L. S.; BARROS, G.; BORBA, W. F.; UCKER, F. E.; FOLETTO, C. V. Caracterização química da água subterrânea em área ocupada por cemitério: uso da técnica de espectrometria de fluorescência de raios-X por energia dispersiva (EDXRF). Ambi-Agua, Taubaté, v. 7, n. 3, p. 166-182, 2012. (http://dx.doi.org/10.4136/ambi-agua.911)

MIGLIORINI, R. B. Cemitérios contaminam o meio ambiente: um estudo de caso. Cuiabá: Universitária, $2002.50 \mathrm{p}$.

PATACA, L. C.; BORTOLETO, G. G.; BUENO, M. I. M. S. Determinação de arsênio em águas contaminadas usando fluorescência de raios-X por energia dispersiva. Química Nova, São Paulo, v. 28, n. 4, p. 579-582. jul./ago. 2005. http://dx.doi.org/10.1590/S010040422005000400004

SERVIÇO GEOLÓGICO DO BRASIL - CPRM. Levantamentos geológicos do Brasil. Brasília: CPRM, 1994. 57 p.

SILVA, V. T.; CRISPIM, J. De Q.; GOCH, P.; KUERTEN, S.; MORAES, A. C. Da S. De; OLIVEIRA, M. A.; SOUZA, I. A.; ROCHA, J. A. Da. 2006. Um olhar sobre as necrópoles e seus impactos ambientais. In: ENCONTRO DA ASSOCIAÇÃO NACIONAL DE PÓS-GRADUAÇÃO E PESQUISA EM AMBIENTE E SOCIEDẢDE, 3., 23 - 26 maio, Brasília. Comunicação Apresentada no Brasília, 2006. Vol. 1. 1 CDROM.

SILVÉRIO da SILVA, J. L.; MENEGOTTO, E.; MEDEIROS, E. R. Avaliação preliminar dos argilominerais das folhas de Santa Maria e Camobi, Rio Grande do Sul, Brasil. Ciência e Natura, Santa Maria, v. 12, p. 127-132, jan./fev. 1990.

SILVÉRIO da SILVA, J. L. Estudos dos processos de silicificação e calcificação em rochas sedimentares mesozóicas do estado do Rio Grande do Sul. 1997. 157f. Tese (Doutorado em Geologia) - Universidade Federal do Rio Grande do sul, Porto Alegre, 1997.

SILVÉRIO Da SILVA, J. L.; CAMPONOGARA, I.; FRANTZ, L. C.; DRESSLER, V. L.; FLORES, E. M. M.; BESSOUAT, C. et al. Caracterização de áreas de recarga e descarga do SAG em Rivera-Livramento e Artigas-Quaraí. In: FUNDO DAS UNIVERSIDADES. Projeto Sistema Aquífero Guarani - PSAG. No 10. Relatório Final. Montivideo, 2006. 2 vol. p. 94.

SILVÉRIO Da SILVA, J. L.; PEDRON, F. de A.; WERLANG, M. K.; DESCOVI FILHO, L. V.; CABRAL, D. R. Características morfológicas do Membro Alemoa, Formação Santa Maria, RS. In: REUNIÃO SUL-BRASILEIRA DE CIENCIA DO SOLO, 8., 25-28 abr., Santa Maria. Comunicação Apresentada no... Santa Maria: SBCS, 2010. v. 1. p. 1 - 6.

SCHIMIDT, F.; BUENO, M. I. M.; EINZWEILLER, J. Determinação de alguns metais em solos por fluorescência de raios-X de energia dispersiva e redes neurais. In: CONGRESSO BRASILEIRO DE REDES NEURAIS, 4., 2009, São José dos Campos. Comunicação apresentada no... São José dos Campos: SBRN. 1999. p. 396-399.

UNESCO; OMS; WHO. The selection of water quality variables. London: Chapman and Hall, 1992. 60 p.

VASCONCELOS, U.; CALAZAND, G. M. T.; ANDRADE, M. A. G. De; MEDEIROS, L. V. Evidência do antagonismo entre Pseudomonas aeruginosa sobre bactérias indicadoras de contaminação fecal da água. Revista Higiene Alimentar, São Paulo, v. 20, n. 140, p. 127-131, 2006. 
KEMERICH, P. D. C.; SILVA, J. L. S.; BARROS, G.; BORBA, W. F.; UCKER, F. E.; FOLETTO, C. V. Caracterização química da água subterrânea em área ocupada por cemitério: uso da técnica de espectrometria de fluorescência de raios-X por energia dispersiva (EDXRF). Ambi-Agua, Taubaté, v. 7, n. 3, p. 166-182, 2012. (http://dx.doi.org/10.4136/ambi-agua.911)

WASTOWSKI A. D.; DA ROSA G. M.; CHERUBIN M. R.; RIGO J. P G. Caracterização dos níveis de elementos químicos em solo, submetido a diferentes sistemas de uso e manejo, utilizando espectrometria de fluorescência de raios-x por energia dispersiva (EDXRF). Química Nova, São Paulo, v. 33, n.7, p. 1449-1452, mar./abr. 2010. http://dx.doi.org/10.1590/S0100-40422010000700005 